\title{
Grade 2 meningioma and radiosurgery
}

\author{
Rabih Aboukais, MD, ${ }^{1}$ Fahed Zairi, MD, ${ }^{1}$ Jean-Paul Lejeune, MD, PhD, ${ }^{1}$ Emile Le Rhun, MD, ${ }^{1}$ \\ Maximilien Vermandel, PhD, ${ }^{2}$ Serge Blond, MD, PhD, ${ }^{1}$ Patrick Devos, PhD, ${ }^{3}$ \\ and Nicolas Reyns, MD, PhD ${ }^{1}$
}

Departments of ${ }^{1}$ Neurosurgery, ${ }^{2}$ Nuclear Medicine, and ${ }^{3}$ Statistics, Lille University Hospital, Lille, France

\begin{abstract}
OBJECT World Health Organization Grade 2 meningiomas are aggressive tumors associated with a high recurrence rate leading to repeated surgical procedures, which can seriously worsen a patient's neurological status. Although radiosurgery is an increasingly popular technique, its role in the management of Grade 2 meningiomas has yet to be defined. In this study the authors aimed to evaluate radiosurgery in achieving control of proven tumor progression occurring after resection of Grade 2 meningioma.
\end{abstract}

METHODS This retrospective study included consecutive patients who, between 2000 and 2012, had undergone radiosurgery for radiologically proven progression of a previously surgically treated Grade 2 meningioma.

RESULTS Twenty-seven patients were eligible for analysis. There were 9 men and 18 women with a mean age of 59 years. The mean radiation dose was $15.2 \mathrm{~Gy}$ (range 12-21 Gy), and the mean target volume was $5.4 \mathrm{~cm}^{3}$ (range $0.194-$ $14.2 \mathrm{~cm}^{3}$ ). Thirty-four radiosurgical procedures were performed in the 27 patients. The mean progression-free survival after radiosurgery was 32.4 months among those with progression in a target irradiated volume and 26.4 months among those with progression in any intracranial meninges. With a mean follow-up of 56.4 months (range 12-108 months), the 12-, 24-, and 36-month actuarial local control rates for all patients were $75 \%, 52 \%$, and $40 \%$, respectively, and the regional control rates were $75 \%, 48 \%$, and $33 \%$. A single case of transient hemiparesis completely resolved without sequelae.

CONCLUSIONS Radiosurgery appears to be a safe and effective treatment for the local control of delayed progression after resection of a Grade 2 meningioma. Higher radiation doses similar to those applied for malignant tumors should be recommended when possible.

http://thejns.org/doi/abs/10.3171/2014.9.JNS14233

KEY WORDS Grade 2 meningioma; radiotherapy; radiosurgery; tumor progression; stereotactic radiosurgery; oncology

$\mathrm{M}$ ENINGIOMAS are the most common primary intracranial tumors. Usually benign and slow growing, they can sometimes show a histological aggressiveness that categorizes them as Grade 2 or 3 in the WHO classification scheme. ${ }^{28}$ Grade 2 meningiomas include atypical chordoid and clear cell meningiomas. ${ }^{6}$ They are known for their tendency to recur after surgical treatment. ${ }^{19,20}$ The main treatment strategy is resection, which should be as complete as possible while preserving the patient's neurological status. However, resection is often incomplete given the infiltrative nature of these tumors. Moreover, these lesions can penetrate the wall of the venous sinuses or the skull base, making them difficult to remove safely. ${ }^{18}$ Radiosurgery has proven its effectiveness in the treatment of many intracranial tumors, including meningiomas..$^{12,17,27}$ Nevertheless, its role remains to be clarified in the management of Grade 2 meningiomas. ${ }^{11}$ In this retrospective study, we aimed to evaluate radiosurgery in achieving control of proven tumor progression occurring after resection of Grade 2 meningioma.

\section{Methods Inclusion Criteria}

Using the local database, we studied the medical records of all patients treated at our institution for a Grade 2

SUBMITTED January 30, 2014. ACCEPTED September 19, 2014.

INCLUDE WHEN CITING Published online March 6, 2015; DOI: 10.3171/2014.9.JNS14233.

DISCLOSURE The authors report no conflict of interest concerning the materials or methods used in this study or the findings specified in this paper. 
meningioma between 2000 and 2012. There were 73 men and 94 women with a mean age of 53.8 years (range 21-85 years) at diagnosis. All patients had undergone previous surgical treatment that confirmed the diagnosis of Grade 2 meningioma. All patients had undergone an annual clinical and radiological (MRI) follow-up. In the present study, all patients who had undergone radiosurgery for the treatment of radiologically proven tumor progression were eligible for analysis.

\section{Decision Making}

The treatment strategy was systematically decided among multidisciplinary staff. For patients who had undergone gross-total resection (Simpson Grade I or II), tumor progression was defined as the occurrence of newly visible tumor on MRI. For patients who had undergone incomplete resection, tumor progression was defined as an increase in tumor diameter on MRI follow-up. All tumor progressions were asymptomatic, diagnosed during MRI follow-up, and confirmed by the neuroradiologist at our institution. Surgery was systematically considered for tu- mor recurrences larger than $3 \mathrm{~cm}$ in diameter. At our institution, both a critical location and a diameter smaller than $3 \mathrm{~cm}$ make radiosurgery more suitable.

\section{Radiosurgery}

A Leksell stereotactic head frame was applied to the patient's head under local anesthesia. One-millimeterthick CT scans and axial Gd-enhanced MRI slices were obtained. The $3 \mathrm{D}$ constructive interference in steady state (CISS) sequence was also used to better define tumor volume. In all cases, MR and CT image matching was performed to enhance accuracy and eliminate possible distortions of MR sequences. After multimodal imaging acquisition, the target localization for radiosurgery was defined using Leksell GammaPlan software. A team composed of a neurosurgeon, a radiation oncologist, and a medical physicist performed the treatment planning.

\section{Clinical and Radiological Follow-Up}

The first posttreatment MRI was performed at 6 months after radiosurgery, and then all patients had an an-

TABLE 1. Summary of main demographic data in 27 patients with Grade 2 meningioma

\begin{tabular}{|c|c|c|c|c|c|c|c|c|c|}
\hline $\begin{array}{c}\text { Case } \\
\text { No. }\end{array}$ & $\begin{array}{c}\text { Age (yrs), } \\
\text { Sex }\end{array}$ & $\begin{array}{l}\text { Location } \\
\text { of Tumor } \\
\text { Recurrence }\end{array}$ & $\begin{array}{c}\text { No. of Resections } \\
\text { Before Radiosurgical } \\
\text { Treatment }\end{array}$ & $\begin{array}{l}\text { Simpson } \\
\text { Grade }\end{array}$ & $\begin{array}{c}\text { No. of Preop } \\
\text { Radiotherapies } \\
\text { (Gy) }\end{array}$ & $\begin{array}{l}\text { Delay Btwn } \\
\text { Surgery \& } \\
\text { RS (yrs) }\end{array}$ & $\begin{array}{l}\text { Radiation } \\
\text { Dose in } \\
\text { SRS (Gy) }\end{array}$ & $\begin{array}{l}\text { Tumor } \\
\text { Control }\end{array}$ & $\begin{array}{c}\mathrm{FU} \\
\text { (mos) }\end{array}$ \\
\hline 1 & $22, F$ & CS & 1 & IV & 0 & 3 & 15 & - & 96 \\
\hline 2 & $39, F$ & SS & 1 & IV & 0 & 7 & 14 & + & 24 \\
\hline 3 & $39, \mathrm{M}$ & SS & 1 & II & 0 & 2 & 14 & + & 21 \\
\hline 4 & $93, \mathrm{~F}$ & LS & 1 & IV & 0 & 4 & 20 & - & 108 \\
\hline 5 & $79, \mathrm{~F}$ & Convexity & 1 & 1 & 0 & 3 & 13 & + & 21 \\
\hline 6 & $35, \mathrm{M}$ & CS & 2 & I, IV & 0 & 1.5 & 15 & - & 52 \\
\hline 7 & $81, \mathrm{~F}$ & LS & 1 & IV & 0 & 1 & 13 & + & 24 \\
\hline 8 & $46, M$ & SS & 1 & II & 0 & 1.5 & 14 & - & 16 \\
\hline 9 & $40, M$ & SS & 1 & II & $1(50)$ & 6 & 14 & + & 12 \\
\hline 10 & $49, F$ & SS & 1 & IV & 0 & 6 & 15 & + & 24 \\
\hline 11 & $64, \mathrm{M}$ & SS & 2 & III, IV & 0 & 6 & 18 & - & 72 \\
\hline 12 & $62, \mathrm{~F}$ & SS & 1 & IV & 0 & 7 & 14 & + & 36 \\
\hline 13 & $80, M$ & SS & 1 & II & 0 & 3 & 13 & - & 39 \\
\hline 14 & $59, F$ & SS & 2 & IV, IV & 0 & 2 & 14 & - & 72 \\
\hline 15 & $84, F$ & SS & 1 & III & 0 & 3 & 12 & - & 21 \\
\hline 16 & $63, \mathrm{M}$ & SS & 1 & IV & $1(54)$ & 2 & 18 & - & 40 \\
\hline 17 & $64, \mathrm{~F}$ & SF & 2 & II, IV & $1(54)$ & 3 & 15 & - & 48 \\
\hline 18 & $36, F$ & Convexity & 2 & $\mathrm{I}, \mathrm{I}$ & 0 & 3 & 13 & - & 54 \\
\hline 19 & $66, F$ & Convexity & 2 & III, II & $1(50)$ & 1 & 15 & - & 64 \\
\hline 20 & $62, \mathrm{M}$ & Convexity & 2 & I, II & $1(50)$ & 4 & 15 & + & 12 \\
\hline 21 & $76, F$ & SS & 1 & IV & $1(54)$ & 1 & 15 & - & 15 \\
\hline 22 & $54, \mathrm{~F}$ & LS & 2 & IV, IV & 0 & 9 & 14 & + & 12 \\
\hline 23 & $65, F$ & SS & 2 & IV, IV & 0 & 2 & 21 & - & 62 \\
\hline 24 & $75, \mathrm{M}$ & SS & 4 & I, II, IV, IV & $1(54)$ & 5 & 14 & - & 12 \\
\hline 25 & $43, F$ & SS & 3 & II, III, IV & $1(54)$ & 0.6 & 16 & - & 48 \\
\hline 26 & $46, \mathrm{~F}$ & SS & 1 & IV & 0 & 0.6 & 21 & - & 108 \\
\hline 27 & $78, F$ & MC & 1 & IV & 0 & 0.6 & 15 & + & 42 \\
\hline
\end{tabular}

CS = cavernous sinus; FU = follow-up; LS = lateral sinus; MC = Meckel's cave; SF = sylvian fissure; SRS = stereotactic radiosurgery; $S S$ = superior sagittal sinus. 


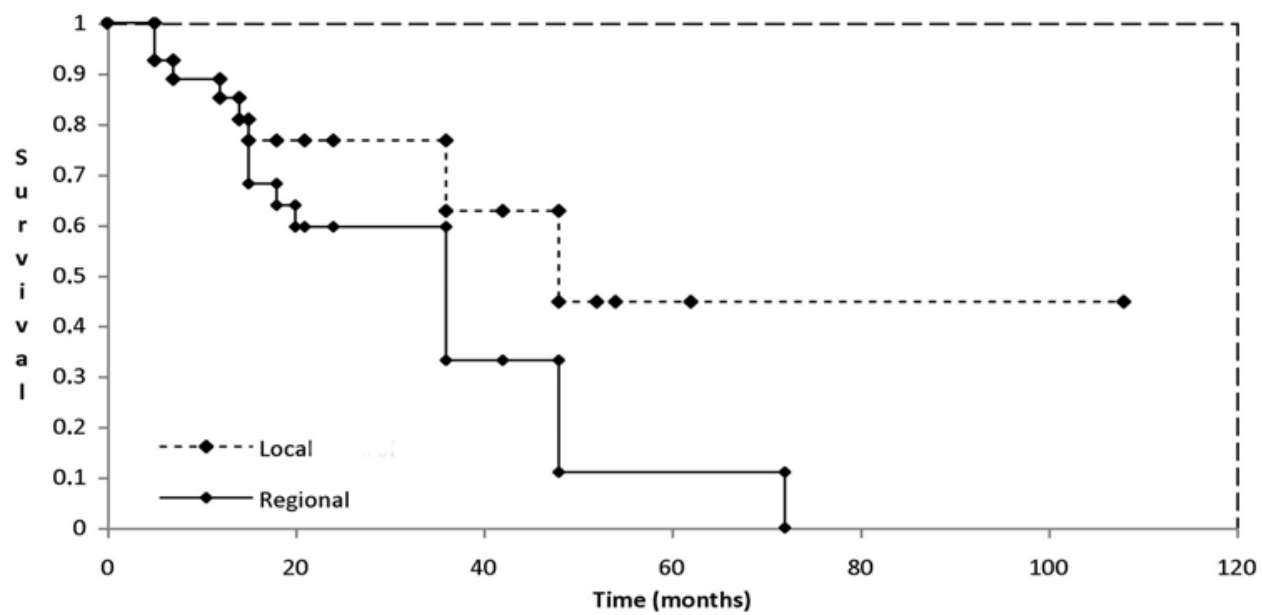

FIG. 1. Kaplan-Meier plot of time to local and regional progression.

nual MRI follow-up. A contrast-enhanced TI-weighted sequence was used to measure the tumor size. Tumor control was defined either by a reduction in tumor size or by its stability in all axes. If suspected, tumor progression was systematically confirmed by the neuroradiologist at our institution.

\section{Statistical Analysis}

Data were recorded using Excel software. Survival curves were computed using Kaplan-Meier estimates. The log-rank test and Cox model were used to compare survival according to categorical or continuous parameters. The analyses were performed using the SAS statistical software, version 9.3 (SAS Institute). A p value $<0.05$ was considered as statistically significant.

\section{Results}

\section{Patient and Tumor Characteristics}

Among all of the patients monitored for Grade 2 meningioma in the defined study period, 27 had proven radiological progression treated with radiosurgery (Table 1). There were 9 men and 18 women with a mean age of 59 years (range 22-84 years). The mean tumor progressionfree period following the prior resection was 39 months (range 6-108 months). The tumor recurrence was located on the superior sagittal sinus in 16 cases, on the convexity in 4 cases, on the lateral sinus in 3 cases, in the cavernous sinus in 2 cases, in Meckel's cave in 1 case, and in the sylvian fissure in 1 case. Thirty-four radiosurgical procedures were performed in the 27 patients. The mean dose of radiation was $15.2 \mathrm{~Gy}$ (range 12-21 Gy), and the mean target volume was $5.4 \mathrm{~cm}^{3}$ (range $0.194-14.2 \mathrm{~cm}^{3}$ ). The lowest doses were applied to tumors near critical structures (for example, optic pathways, brainstem). The mean follow-up period was 56.4 months (range 12-108 months), and no patient was lost to follow-up.

\section{Tumor Control}

During the postradiosurgical follow-up period, 17 patients harbored tumor progression, which was in the irra- diated target volume (local) in 8 patients and in the other intracranial meninges (regional) in 9 patients (limit of the target irradiated volume or at a distance). The mean progression-free survival after radiosurgery was 32.4 months among those with progression in a target irradiated volume and 26.4 months among those with progression in any intracranial meninges.

With a mean follow-up of 56.4 months (range 12-108 months), the 12-, 24-, and 36-month actuarial local control rates for all patients were $75 \%, 52 \%$, and $40 \%$, respec-
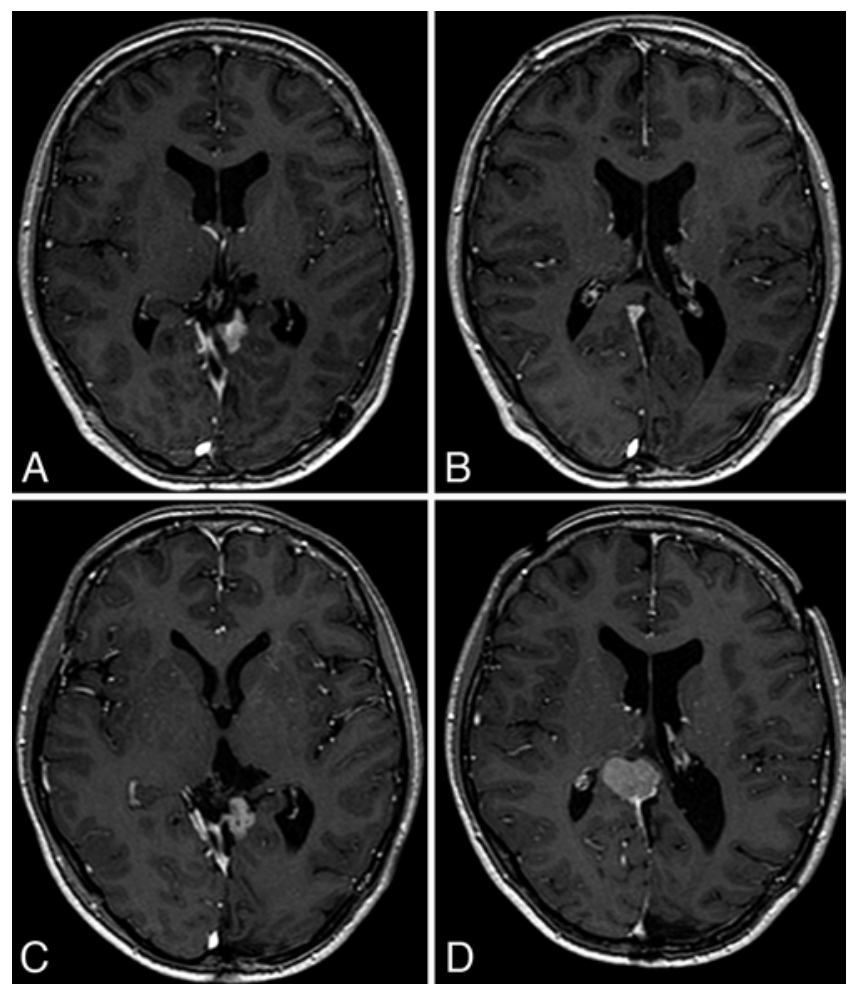

FIG. 2. Case 3. Postoperative MRI at 2 years. Left-sided progression that required radiosurgery in 2007 (A and B). In 2009, although the treated tumor was still controlled (C), MRI revealed a new right-sided progression that required a new radiosurgical procedure (D). 
TABLE 2. Results of a univariate analysis of factors that may have affected local and regional tumor control ${ }^{*}$

\begin{tabular}{lcc}
\hline \multirow{2}{*}{ Factor } & \multicolumn{2}{c}{$p$ Value } \\
\cline { 2 - 3 } & Local Control & Regional Control \\
\hline Age & $\mathbf{0 . 0 4 9 6}$ & 0.3436 \\
\hline Sex & 0.0951 & $\mathbf{0 . 0 3 3 3}$ \\
\hline Location of recurrence & 0.6976 & 0.8540 \\
\hline Simpson grade & 0.6905 & 0.7051 \\
\hline No. of resections & 0.9164 & $\mathbf{0 . 0 3 1 0}$ \\
\hline Postop radiotherapy & 0.6250 & $\mathbf{0 . 0 2 5 4}$ \\
\hline Delay btwn surgery \& SRS & 0.6082 & 0.8397 \\
\hline Radiation dose & 0.3984 & 0.6507 \\
\hline Target volume & $\mathbf{0 . 0 4 4 5}$ & 0.1374 \\
\hline
\end{tabular}

* Values in boldface type indicate significance.

tively, and the regional control rates were $75 \%, 48 \%$, and $33 \%$ (Fig. 1).

Among the 8 patients with progression in the target volume, only 3 have benefited from a new radiosurgical procedure at a mean dose of 14.3 Gy (range 14-15 Gy). Surgery was required for the other 5 cases. As regards the effectiveness of radiosurgery in the treated volume, 6 of the 9 patients who presented with regional progression benefited from a new radiosurgical procedure at a mean dose of 15.7 Gy (range 15-18 Gy; Fig. 2), whereas 3 patients required surgery because of the tumor size. For all patients who required resection, histological analysis confirmed the same diagnosis of Grade 2 meningioma with no sign of radionecrosis. Four of these 17 patients underwent radiotherapy for the treatment of delayed progression not accessible by surgery. No related morbidity has been reported.

\section{Univariate Analysis}

Regarding local tumor control, patient age and target volume have been shown to bear some predictive value but only at a level of slight significance (Table 2). Regarding regional tumor control, women have demonstrated a lower rate of regional progression $(\mathrm{p}=0.0333)$. The number of resections was associated with poorer regional control $(\mathrm{p}$ $=0.0310$ ). Patients who underwent postoperative radiotherapy demonstrated better regional control $(p=0.0254)$.

\section{Morbidity}

We reported 1 case of transient hemiparesis occurring a few days after the treatment of a tumor located on the sagittal sinus, close to the motor area. This complication was related to an increase in edema, which required increasing the steroid therapy. No other complication has been reported. This represents an overall complication rate of $3.7 \%$ per patient and $2.9 \%$ per procedure.

\section{Discussion}

\section{Natural History of Grade 2 Meningioma}

Grade 2 meningiomas are progressive tumors. The rate of progression-free survival of patients with Grade 2 meningiomas is approximately $50 \%$ at 5 years. ${ }^{6,26}$ Multiple surgical procedures are usually required to control tumor recurrences. Repeated surgeries are associated with increased morbidity, which can seriously affect a patient's quality of life. ${ }^{22}$ Recently, committees of neurooncologists have proposed performing external radiotherapy at an early stage in patients with Grade 2 or 3 meningiomas ${ }^{1,2,7}$ to improve progression-free survival time. However, radiotherapy is not without risk. First, radionecrosis is a well-known life-threatening complication of radiotherapy. ${ }^{4}$ Second, malignant transformations have also been reported, especially in patients with neurofibromatosis Type $2.8,23$ Third, radiotherapy can induce delayed cognitive disorders, especially in elderly patients, resulting in loss of autonomy ${ }^{25}$ As there is still no consensus regarding the ideal management of such tumors, the morbidity resulting from these 2 treatment methods should be taken into account during the management of Grade 2 meningiomas.

\section{Goals of Radiosurgery}

To overcome these drawbacks of resection and radiotherapy, radiosurgery has been proposed as a valuable treatment strategy. ${ }^{21}$ The adverse effects of this noninvasive technique are rare. ${ }^{10,16}$ In our study, we reported a single case of transient hemiparesis that completely resolved without sequelae. Although radiosurgery is a safe therapeutic option, it can only be performed for tumors of limited size. Some authors ${ }^{11,15}$ have demonstrated the benefit of radiosurgery in achieving local control of residual tumor after an incomplete resection. This initial combined treatment has been proposed to limit the functional risk for tumors located in critical areas. Few authors $3,5,9,15,20$

TABLE 3. Literature summary of the main clinical studies on Grade 2 meningioma treated with stereotactic radiosurgery

\begin{tabular}{|c|c|c|c|c|c|c|}
\hline Authors \& Year & No. of Patients & $\begin{array}{l}\text { Radiosurgical Procedure } \\
\text { (no. of fractions) }\end{array}$ & $\begin{array}{l}\text { Mean Dose } \\
\text { (Gy) }\end{array}$ & $\begin{array}{l}\text { Mean Tumor } \\
\text { Vol }\left(\mathrm{cm}^{3}\right)\end{array}$ & $\begin{array}{c}\text { Local PFS ( } \% \text { patients } \\
\text { at } 1-2-3 \text { yrs) }\end{array}$ & $\begin{array}{l}\text { FU } \\
\text { (mos) }\end{array}$ \\
\hline Choi et al., 2010 & 25 & $1-4$ & 22 & 5.3 & $100-100-73$ & 28 \\
\hline Attia et al., 2012 & 24 & 1 & 14 & $?$ & $75-51-?$ & 42.5 \\
\hline Ferraro et al., 2014 & 31 & 1 & 18 & 3.9 & 95.7-?-70.1 & 34.5 \\
\hline Kim et al., 2012 & 35 & 1 & 16 & 3.5 & $78-53-36$ & NA \\
\hline Mori et al., 2013 & 30 (24 w/ G2; 6 w/ G3) & 1 & $?$ & $?$ & $74-52-34$ & 28 \\
\hline Present study & 27 & 1 & 15.2 & 5.4 & $75-52-40$ & 56.4 \\
\hline
\end{tabular}

? = unknown; G2, G3 = Grade 2, Grade 3; NA = not available; PFS = progression-free survival. 
have reported the outcomes of patients who underwent stereotactic radiosurgery for the treatment of Grade 2 meningioma (Table 3 ). The local tumor control rates were very similar to those we reported in this study, even if the follow-up was limited. Choi et al. ${ }^{5}$ described a series of 25 patients with local control rates of 100\%, 100\%, and 73\% and regional control rates of $93 \%, 93 \%$, and $75 \%$ at 12 , 24, and 36 months, respectively. However, in their series, 15 patients were treated for residual tumor immediately after surgery, whereas only 10 patients were treated for delayed, radiologically proven tumor progression. In our study, we focused only on patients who had undergone radiosurgery for the treatment of radiologically proven progression occurring during the postoperative follow-up. Radiosurgery was preferred for tumors of limited size and located in critical areas such as the venous sinuses or the motor area. ${ }^{3}$ For patients who developed tumor progression after radiosurgery, further treatments were still feasible without evidence of increased morbidity. Indeed, in our series, 8 patients required resection after radiosurgery without reported technical difficulties or morbidity. As tumor recurrence often occurs outside the target volume, ${ }^{3,15}$ a new radiosurgical procedure can also be performed. In our series, 6 patients benefited from this type of repeated treatment. When indicated, radiotherapy can also be performed after radiosurgery. ${ }^{13}$

\section{Limits of Radiosurgery}

As Grade 2 meningioma corresponds to a diffuse involvement of the meninges, wide resection followed by postoperative radiotherapy should be performed when possible at the initial management. Some recent studies have demonstrated that initial radiotherapy improves progression-free survival ${ }^{1,2,20}$ and should be performed except for patients at risk. In our series, postoperative radiotherapy was also a protective factor regarding regional tumor control. In our opinion, radiosurgery should not serve as a substitute for surgery and radiotherapy but instead should be considered as a complementary therapeutic tool in case of tumor progression of limited size and located in critical areas.

There is still no consensus regarding the ideal radiation dose. Several studies ${ }^{12,15,24}$ have demonstrated that a dose of $15 \mathrm{~Gy}$ is sufficient to obtain good local control of Grade 1 meningiomas. Many teams have applied similar doses for the treatment of Grade 2 meningiomas. In recent years, some authors ${ }^{3,5,14}$ have advocated applying higher doses similar to those applied for malignant tumors. In our study, the relatively high tumor recurrence rate could be explained by an insufficient mean radiation dose (15.2 Gy). Nevertheless, such a dose cannot be applied to tumors close to visual pathways or the brainstem. In our series, the radiation dose was not a statistically significant factor for local control, but our results should be interpreted carefully because of the limited cohort of patients.

The management of Grade 2 meningiomas requires very close monitoring to diagnose any tumor progression as early as possible, and patient compliance is mandatory. Each tumor progression of limited size, especially in critical areas, can be treated with radiosurgery, which can also be repeated during the follow-up.

\section{Study Limitations}

The main limitation of our study is its retrospective nature. In addition, we reported on a limited cohort of patients with a wide range of radiation doses, which limits the validation of our results. Moreover, our cohort was heterogeneous as some patients (Table 1) underwent postoperative radiation therapy prior to the radiosurgical procedure. Hence, a prospective study including a larger cohort of patients would be suitable to precisely define the role of radiosurgery and to better define the ideal radiation dose.

\section{Conclusions}

Radiosurgery appears to be a safe and effective treatment for local control of delayed progression after the resection of a Grade 2 meningioma. Higher radiation doses similar to those applied for malignant tumors should be recommended when possible.

\section{References}

1. Aboukais R, Baroncini M, Zairi F, Reyns N, Lejeune JP: Early postoperative radiotherapy improves progression free survival in patients with grade 2 meningioma. Acta Neurochir (Wien) 155:1385-1390, 2013

2. Adeberg S, Hartmann C, Welzel T, Rieken S, Habermehl D, von Deimling A, et al: Long-term outcome after radiotherapy in patients with atypical and malignant meningiomas-clinical results in 85 patients treated in a single institution leading to optimized guidelines for early radiation therapy. Int $\mathbf{J}$ Radiat Oncol Biol Phys 83:859-864, 2012

3. Attia A, Chan MD, Mott RT, Russell GB, Seif D, Daniel Bourland J, et al: Patterns of failure after treatment of atypical meningioma with gamma knife radiosurgery. J Neurooncol 108:179-185, 2012

4. Carangelo B, Cerillo A, Mariottini A, Peri G, Rubino G, Mourmouras V, et al: Therapeutic strategy of late cerebral radionecrosis. A retrospective study of 21 cases. J Neurosurg Sci 54:21-28, 2010

5. Choi CY, Soltys SG, Gibbs IC, Harsh GR, Jackson PS, Lieberson RE, et al: Cyberknife stereotactic radiosurgery for treatment of atypical (WHO grade II) cranial meningiomas. Neurosurgery 67:1180-1188, 2010

6. Durand A, Labrousse F, Jouvet A, Bauchet L, Kalamaridès M, Menei P, et al: WHO grade II and III meningiomas: a study of prognostic factors. J Neurooncol 95:367-375, 2009

7. Engenhart-Cabillic R, Farhoud A, Sure U, Heinze S, Henzel $\mathrm{M}$, Mennel HD, et al: Clinicopathologic features of aggressive meningioma emphasizing the role of radiotherapy in treatment. Strahlenther Onkol 182:641-646, 2006

8. Evans DG, Birch JM, Ramsden RT, Sharif S, Baser ME: Malignant transformation and new primary tumours after therapeutic radiation for benign disease: substantial risks in certain tumour prone syndromes. J Med Genet 43:289-294, 2006

9. Ferraro DJ, Funk RK, Blackett JW, Ju MR, DeWees TA, Chicoine MR, et al: A retrospective analysis of survival and prognostic factors after stereotactic radiosurgery for aggressive meningiomas. Radiat Oncol 9:38, 2014

10. Girvigian MR, Chen JC, Rahimian J, Miller MJ, Tome M: Comparison of early complications for patients with convexity and parasagittal meningiomas treated with either stereotactic radiosurgery or fractionated stereotactic radiotherapy. Neurosurgery 62 (5 Suppl):A19-A28, 2008

11. Hardesty DA, Wolf AB, Brachman DG, McBride HL, Youssef E, Nakaji P, et al: The impact of adjuvant stereotactic radiosurgery on atypical meningioma recurrence 
following aggressive microsurgical resection. J Neurosurg 119:475-481, 2013

12. Hasegawa T, Kida Y, Yoshimoto M, Iizuka H, Ishii D, Yoshida K: Gamma Knife surgery for convexity, parasagittal, and falcine meningiomas. J Neurosurg 114:1392-1398, 2011

13. Jensen AW, Brown PD, Pollock BE, Stafford SL, Link MJ, Garces YI, et al: Gamma knife radiosurgery of radiationinduced intracranial tumors: local control, outcomes, and complications. Int J Radiat Oncol Biol Phys 62:32-37, 2005

14. Kano H, Takahashi JA, Katsuki T, Araki N, Oya N, Hiraoka $\mathrm{M}$, et al: Stereotactic radiosurgery for atypical and anaplastic meningiomas. J Neurooncol 84:41-47, 2007

15. Kim JW, Kim DG, Paek SH, Chung HT, Myung JK, Park SH, et al: Radiosurgery for atypical and anaplastic meningiomas: histopathological predictors of local tumor control. Stereotact Funct Neurosurg 90:316-324, 2012

16. Kreil W, Luggin J, Fuchs I, Weigl V, Eustacchio S, Papaefthymiou G: Long term experience of gamma knife radiosurgery for benign skull base meningiomas. J Neurol Neurosurg Psychiatry 76:1425-1430, 2005

17. Lee JY, Kondziolka D, Flickinger JC, Lunsford LD: Radiosurgery for intracranial meningiomas. Prog Neurol Surg 20:142-149, 2007

18. Mantovani A, Di Maio S, Ferreira MJ, Sekhar LN: Management of meningiomas invading the major dural venous sinuses: operative technique, results, and potential benefit for higher grade tumors. World Neurosurg 82:455-467, 2014

19. Modha A, Gutin PH: Diagnosis and treatment of atypical and anaplastic meningiomas: a review. Neurosurgery 57:538550,2005

20. Mori Y, Tsugawa T, Hashizume C, Kobayashi T, Shibamoto Y: Gamma knife stereotactic radiosurgery for atypical and malignant meningiomas. Acta Neurochir Suppl 116:85-89, 2013

21. Perry A, Stafford SL, Scheithauer BW, Suman VJ, Lohse CM: Meningioma grading: an analysis of histologic parameters. Am J Surg Pathol 21:1455-1465, 1997
22. Poon MT, Fung LH, Pu JK, Leung GK: Outcome comparison between younger and older patients undergoing intracranial meningioma resections. J Neurooncol 114:219-227, 2013

23. Shin M, Ueki K, Kurita H, Kirino T: Malignant transformation of a vestibular schwannoma after gamma knife radiosurgery. Lancet 360:309-310, 2002

24. Stafford SL, Pollock BE, Foote RL, Link MJ, Gorman DA, Schomberg PJ, et al: Meningioma radiosurgery: tumor control, outcomes, and complications among 190 consecutive patients. Neurosurgery 49:1029-1038, 2001

25. Taillia H, Bompaire F, Jacob J, Noël G: [Cognitive evaluation during brain radiotherapy in adults: a simple assessment is possible.] Cancer Radiother 17:413-418, 2013 (Fr)

26. Yamasaki F, Yoshioka H, Hama S, Sugiyama K, Arita K, Kurisu K: Recurrence of meningiomas. Cancer 89:11021110, 2000

27. Zada G, Pagnini PG, Yu C, Erickson KT, Hirschbein J, Zelman V, et al: Long-term outcomes and patterns of tumor progression after gamma knife radiosurgery for benign meningiomas. Neurosurgery 67:322-329, 2010

28. Zhou P, Ma W, Yin S, Li Y, Jiang S: Three risk factors for WHO grade II and III meningiomas: a study of 1737 cases from a single center. Neurol India 61:40-44, 2013

\section{Author Contributions}

Conception and design: Aboukais. Acquisition of data: Aboukais, Zairi, Vermandel. Drafting the article: Zairi, Reyns. Critically revising the article: Blond, Reyns. Reviewed submitted version of manuscript: Lejeune, Le Rhun. Statistical analysis: Le Rhun, Devos. Study supervision: Lejeune.

\section{Correspondence}

Rabih Aboukais, Department of Neurosurgery, Lille University Hospital, rue E. Laine, 59037 Lille cedex, France. email: rabihdoc@hotmail.com. 